\title{
Towards an Eco-social Food System: The Shift from Industrial Agriculture to Agro-ecology in South Africa
}

\author{
Michael Rudolph ${ }^{1, *}$, Evans Muchesa ${ }^{2}$, Florian Kroll ${ }^{2}$ \\ ${ }^{1}$ Centre for Ecological Intelligence, Office of the Vice Chancellor, University of Johannesburg, Johannesburg, South Africa \\ ${ }^{2}$ Research and Project Development, Siyakhana Growth and Development NPO, Johannesburg, South Africa
}

Email address:

michaelr@uj.ac.za (M. Rudolph), evans@siyakhana.org (E. Muchesa)

${ }^{*}$ Corresponding author

\section{To cite this article:}

Michael Rudolph, Evans Muchesa, Florian Kroll. Towards an Eco-social Food System: The Shift from Industrial Agriculture to Agro-ecology in South Africa. International Journal of Sustainable Development Research. Vol. 6, No. 2, 2020, pp. 22-29. doi: 10.11648/j.ijsdr.20200602.11

Received: April 7, 2020; Accepted: May 6, 2020; Published: May 28, 2020

\begin{abstract}
Input-intensive industrial-scale production systems are not sustainable means of addressing issues such as food security, nutrition security and sustainable livelihoods. Several literatures suggest that the solution to world hunger is to diversify agriculture and reorient it around ecological practices. There is considerable evidence that supports agro-ecological farming system ss a viable alternative that can improve food production especially for the most vulnerable farming households. In addition, literature shows that an agro-ecology food system holds the key to increasing dietary diversity at the local level, as well as reducing the multiple health risks from industrial agriculture. This paper is aimed at discussing the benefits of agro-ecology food system and how agricultural support systems can play a role. The emphasis of the paper is the application of the agro-ecology approach in an urban/ peri-urban setting. An evaluation report of City of Johannesburg (CoJ) Food Resilience Programme Evaluation unpublished report (2016), shows that very few households engage in gardening/ urban agriculture either in their backyards or nearby open spaces due to the following reasons; strict city by-laws, no access to land, no knowledge of innovative/alternative farming practices lack of interest and limited resources.
\end{abstract}

Keywords: Agro-ecology, Food Security, Urban Agriculture, Food Systems, Biodiversity

\section{Introduction}

Several studies have shown that low input small-scale agriculture has huge potential in addressing food insecurity in urban, peri-urban and rural environments compared to conventional industrialized agriculture. Agro-ecology is categorized as a science and a socio-political movement. In context of the study, agro-ecology is based on shared ownership and responsibility for natural resources which include land, seeds, livestock, water, and knowledge (the global commons). Crucial resources are managed through collective, democratic control, framed through public policies. Other descriptions of agro-ecology include building sustainable local food economies by supporting all the stakeholder holders in the food chain. These include local producers, processors and retailers, and building links between consumers, local farmers and local food businesses. A decentralized short supply chains, diversified markets based on solidarity and fair prices, and closer links between producers and consumers locally, is critical in increasing food access to the most vulnerable households. $[1,3,4,7]$.

\section{Problem Statement}

In South Africa, both rural and urban vulnerable populations in distressful and protracted emergencies, find their resilience to food insecurity is being severely corroded. Vulnerable households find themselves bogged down to fare for subsistence and survival from their physical insecurities According to the CoJ Food Resilience Report in Johannesburg between half and three quarters of people in poor areas are affected by food insecurity and food is the biggest household expense in most poor households. In South Africa, the levels of food insecurity are locally specific; food insecurity is more widespread in informal settlements and in peri-urban areas. There is growing evidence that urban agriculture, especially agro-ecology, is essential in addressing food insecurities to the 
most vulnerable households in South Africa. Despite many studies in food security, urban agriculture and agro-ecology, there is a need for more programmatic solutions and approaches in addressing food insecurity in both urban and rural areas $[4,8,9,12,13]$.

\section{Methodology}

The methodology used for this study is based on structured literature review analysis in the areas of urban agriculture, agro-ecology, food insecurity and food sovereignty. The approach can be explained as a research method and process for identifying and critically appraising relevant research, as well as collecting and analyzing relevant literature and data focusing on agro-ecology in urban setting and related approaches in South Africa and regionally. Most studies which explore successful application of agro-ecology as a food system indicate that it has to be applied both at a micro level (household level) and macro level (local and national level). The micro level entails supplementing and complementing household food supplies for the most vulnerable food insecure households through innovative gardening techniques which are simple and locally available resources. At macro-level, they are the type of interventions which capitalise on the land use patterns of the city, so as to improve the local food system, by leveraging on the social and economic dynamism such as supply chains, collaboration with local farms in the vicinity and other stakeholders so as to improve food access and distribution $[11,13,14,15]$.

\section{Literature Review}

\subsection{Defining Agro-ecology}

Agro-ecology is defined as a science, a social and political movement. Agro-ecology as a science is an "application of ecological science to the study, design and management of sustainable agro-eco systems". This applies not only at the farm-level, but also across the global network of food production, distribution and consumption. This definition considers knowledge from a range of disciplines which includes agricultural and ecological science, and traditional knowledge systems. Agro-ecology as a social and political movement explores as to how individuals, communities and societies contribute to building sustainable, fair food models by what they buy, in which way they shop and organize food distribution. Agro-ecological movements seek to influence national and international policies through grassroots cooperation, participation and action to create more sustainable food management systems [1, 3, 5, 11, 14].

\subsection{Agro-ecology, Food Security and Food Sovereignty}

A viable option for enhanced Food Security is embedded in the key features of agro-ecology which are improvement of productivity over time at the farm level and across the whole food supply chain. This tends to benefit the farmer by providing different sources of income, reduces risk of crop failures, and provides a wider range of food which can improve diets. Food security and food sovereignty are important components when looking at agro-ecology/eco-agriculture However, it is important to firstly define the terms food security and food sovereignty and then establish the link with agro-ecology [7, 13].

The following definitions of food security and food sovereignty are important concepts, in agro-ecology. Food Security is defined- as the existence of food security when all people, always have physical, social and economic access to sufficient safe and nutritious food that meets their dietary needs and food preferences for an active and healthy life. Then Food Sovereignty as "the right of peoples to healthy and culturally appropriate food produced through ecologically sound and sustainable methods, and their right to define their own food and agriculture systems" Food insecurity should be seen in the context of affordability and accessibility and not simply an issue of how much food is produced. Thus, a developmental model that encourages agri-business organisations to embrace the concept of food security (allowing access to affordable and nutritious food all times) is critical in reducing food insecurities among the most vulnerable households and individuals in our society [20, 21].

Greater attention to the issue of food sovereignty has been brought to the fore by civil society responses in Latin America, Asia, and Africa that organised transnational movements of small peasants and landless people. The first of these were global networks such as La Via Campesina and the Agricultures Network (former LEISA). Experiences came also from Africa with ROPPA (Réseau des Organisations Paysannes et des Producteurs Agricoles de l' Afrique de l' Ouest) and PELUM network (Participatory Ecological Land Use Management); from Brasil with AS-PTA ( Assessoria e Serviços a Projetos em Agricultura Alternativa) and MST (Movimento dos Trabalhadores Sem Terra; from the Philippines with MASIPAG ( Magsasaka at Siyentista Tungo sa Pag-unlad ng Agrikultura). In addition, attention on land and agrarian transformation that gives a country the right to achieve food sovereignty is important. The feature of the transformation should be based on food sovereignty which includes local production, agricultural prices directly linked to producing costs, the right of countries to protect themselves against dumping of underpriced agricultural produce [17-19].

About 50 to 75 percent of the world food is produced by smallholder farmers, controlling 25-30 percent of the land and using only 30 percent of the water and 20 percent of the fossil fuels used in the agricultural sector worldwide. Throughout the world more than 90 percent of the farms are categorized as small (which is less than 2 hectares). These farms contribute to the agricultural biodiversity by breeding 7, 616 animal species and 1.9 million crop varieties. Small farms are considered to be more productive then large farms. They tend to use locally available resources in efficient methods and rely on indigenous knowledge systems. Smallholder farmers are the custodians of agricultural biodiversity, repositories of indigenous knowledge, producers of food and innovators. They use agro-ecological techniques such as intercropping 
and other innovative techniques. So, for countries to achieve food security and food sovereignty status, they need to support their smallholder farmers [13, 15, 22].

\subsection{Concept of Agro-ecology in an Urban Setting}

While agro-ecology has been constrained to a primarily rural context, food sovereignty is not only a rural issue but also affects city people. The current model of agri-business undermines food sovereignty. This model, which encompasses the lack of agrarian reforms, droughts, ecological degradation and conflicts are all factors that, accompanied with high birth rates, contribute to the growth of cities, while the diminution in agricultural production for local consumption encourages food imports, exacerbating the vicious cycle. Millions of people choose to abandon the countryside to escape hunger, poverty and insecurity. Even when they reach and settle in the cities, they end up poorer, often without employment, living in polluted environments, with no secure housing and poor or no access to basic health, water and sanitation services. The hopes of these people rarely translate into prosperity [5, 23].

The proportion of people living in urban areas was greater than 50 percent. FAO estimates that there are 2.5 billion people living in urban areas today in the developing world and forecast 3, 5 billion dwellers in 2025. This incredibly fast urbanization is transforming the already vulnerable city-environments into degraded and impoverished settlements with populations that are spatially marginalised, socially excluded and unemployed. It is challenging urban food systems to expand and become more efficient and equitable. Using the results of the 2011 census, two-thirds of South Africa's population now lives in urban areas, people living in urban areas now is at $62 \%$ and those living in rural areas have dropped to $38 \%$. Food insecurity is on the rise in the urban areas because of the increase in urban population. The urban poor spend most of their income in food and thus they become highly vulnerable when food prices increase. This has multiple effects on their health status. For some, inaccessibility translates into under nutrition, for others lack affordability contributes to malnutrition, obesity and non-communicable diseases. These people rely on the purchase of cheap food which is highly caloric, deficient in vitamins and minerals, rich in starch, containing hydrogenated fats and simple sugars, while their daily intake of fruit and vegetables is under half the minimum level recommended by the World Health Organization 2015 [9, 26].

The reasons for diminished food access and nutritional inequalities among the urban poor which include the gradual reduction of fresh produce markets, caused by urban development pressures and by the so called "supermarketisation" phenomenon. Use of land is mostly allocated to industry and housing with the consequent production of fresh food pushed from peri-urban to rural areas. The cost of packaging, transport and refrigeration and losses along this chain affects the availability and the final value of food in the urban markets while local food retailers are displaced by marketplace activities of corporate chains $[1,3$,
8].

Furthermore, small food producers and retailers are not able to meet food safety standards laid down by the international agencies and corporate policies in the context of world commodity trade as well as local food, health and safety regulations. Hence the lack of facilities and hygiene programmes to meet the requirements often result in them closing their activities and losing their income. An important consideration is urban planning as food outlets are mostly accessible by car, which limits the procurement of food for poor dwellers with no transportation while fresh food outlets disappear to accommodate private vehicles $[6,10,11]$.

\subsection{Urban Agriculture and Food Security}

The Southern African cities' framework does not differ much from these global disparity characteristics. The African Food Security Urban Network (AFSUN) estimates that of $77 \%$ of poor households or 100 million people living in urban and peri-urban areas in the Southern African Developing Countries are food insecure. Food insecurity overlays poverty, considering that three quarters of the urban peoples' income is less than 2 dollars a day and almost half of it is spent to purchase food. Although the majority of these households go to the supermarket to buy food, the informal sector remains highly important, with $70 \%$ of people frequently obtaining food from street vendors and two thirds depending on small outlets. Nevertheless, on a daily basis the informal sector remains the most often frequented source of purchase amongst southern African urban poor inhabitants, followed by small outlets and supermarkets; the latter frequented every day by only by $5 \%$ of households Street vendors have higher prices compared to supermarkets but remain the easiest way to purchase food because of the geographical proximity and minimal need for transportation. Furthermore, most poor settlements do not have electricity. The lack of refrigeration in many informal areas limits the possibility to buy bulk fresh food provisions thus most dwellers have to purchase food almost on a daily basis. Finally, urban agriculture for self-subsistence constitutes an important source of food for almost a quarter of poor households, but for only a small amount of people this is a source of income [10,13].

Despite urban agriculture playing a minor role in food supply up to now, its practice is spreading amongst urban poor in Africa. Urban agriculture is carried out by those who have access to land and inputs and those who lack a regular source of income who are not enabled to purchase food. Millions of slum dwellers have turned to agriculture growing their own food illegally in every scrap of available land: along rivers, roads, railways and in backyards. In the Congolese city of Lubumbashi, after the collapse of the giant GECAMINES in '91 urban agriculture within and around the city constituted an alternative strategy for individuals and households seeking to alleviate their poverty and it also generated incomes $[13,15$, 27].

Urban agriculture is not a new idea, agriculture was closely linked to the origin of cities and allowed people to settle 
permanently in organised hubs. It has always been practiced in the North and South of the world and has constituted a strategy of self-sufficiency that allowed people to survive during wars and economic depressions. The value of urban agriculture has been recognised by Non-Governmental Organizations (NGOs), community-based organizations (CBOs) and grass-root movements, which have launched projects in cities and peri-urban areas. Currently international agencies, national governments and local municipalities are sustaining projects that involve this practice. FAO, for example, in collaboration with city municipalities in 20 countries of Latin and South America and Africa, has promoted irrigated commercial market gardening in urban peripheries, hydroponic micro-gardens in slums and green rooftops in city centres. Examples of adoption of national plans and policies that actively promote urban agriculture come from Latin America, Cuba, Argentina, Brazil, Bolivia and China [5, 25, 27].

In Africa, examples of a national development structure for urban and peri-urban agriculture come from the Democratic Republic of Congo, where municipalities are integrating this practice into urban planning and initiating a process of regularizing titles to land for horticulture. The potential of urban agriculture in upgrading informal settlements and ameliorating food access and security of urban dwellers often goes unrecognised in both agricultural policies and urban planning. The sector could play a key role in the food system and in socio-economic development, but it is still hugely understated and unsupported by public institutions which do not provide its practitioners with due assistance neither in terms of inputs and extension nor in terms of incentives for production and distribution $[1,11]$.

A step forward in the acknowledgement of urban/periurban agriculture potential was taken in 2003 by the governments of Zimbabwe, Swaziland, Malawi, Tanzania and Kenya with the Harare Declaration in Urban and Peri-Urban Agriculture. The declaration identified the institutional and resource obstacles to the integration of urban and peri-urban agriculture in urban economies, calling for a shared vision around the sector, but what remains unclear is the translation of this declaration into practice $[13,19]$.

\subsection{State of Urban Agriculture in South Africa}

In South Africa very little is done to include urban/peri-urban agriculture in the economic sector. In some provinces and municipalities, initiatives are slowly attempting to include urban agriculture in health promotion and community programmes. The municipality of Cape Town, for example, supplies community gardening groups with tool, seeds, compost and access to skills training. In 2005, Msunduzi Municipality in Kwazulu-Natal, in partnership with Children in Distress Network and The Institute of Natural Resources, established a programme called the African Root Project which promoted the creation of food gardens across the municipality to address the nutritional needs of the communities affected by HIV/AIDS. In Gauteng, the Department of Education recently launched the Health
Promoting Schools program which included the development of food-gardens in several schools of the province. During 2008 and 2009 the National Household Food Production Programme distributed 80000 "starter packs" which provided basic inputs like seeds, seedlings, fertilizers and pesticides in support to production of food gardens $[1,13,25]$.

Several similar programs in the country have traditionally been run by NGOs, CBOs and other non-profit entities, often with the help of international cooperation. However, these initiatives have been constrained by the Corporate Social Investment (CSI) context which frequently results in programmes which are conceptualised for short-term outcomes, are easily abused as a way for corporations to bolster their corporate image, and are not informed by effective development methodologies. The supply of agricultural inputs and training is a significant step, both in urban and rural contexts. However, in both CSI-based and government-led initiatives, strategies typically remain mired in centralised, top-down extension models which consist of the installation of infrastructure and little and or inadequate training, leaving projects to flounder after the short funding timeframe is concluded. As a result, these kinds of initiatives are rarely sustainable $[1,13,25]$.

These programmes should receive more resources and the responsibility for ensuring their success should be shared by government and civil society in policy agendas with the intention to build self-sufficiency, instead of considering them as emergency-response strategies like grants or food subsidies. Furthermore, these programmes should be capacitated to fully realise the potential of successful producers in moving from a self-subsistence production to a larger scale and thereby generating income. To do so sustainably, it would be essential to develop enduring local resource and demonstration hubs staffed by extension and support teams who can provide training, advice, organisational development, access to inputs and appropriate financial products such as microfinance and insurance [27].

Finally, agriculture projects should be linked to other components of the food system such as processing, packaging, distribution and retailing via local food markets to ensure their longer-term survival. In both the urban and peri-urban hubs thousands of job opportunities and livelihoods could be created by establishing these links. In the urban context cultivation is often isolated from the urban food supply. This is based on the misconception that food insecurity is mainly an issue of inadequate food availability - a belief which frequently informs food security policy. This leads to the mistaken assumption that food insecurity can be resolved through increasing production quantities in the rural areas and among food insecure households. For the same reason, responsibility for food security policies resides primarily with the Department of Agriculture. This problem is aggravated in Gauteng Province where the economy is pushed and pulled by the commercial and industrial sectors while agriculture occupies a marginal place. Consequently, food security planning is not sufficiently acknowledged by other departments. The lack of alignment and collaboration of 
different departments and the lack of coordination between government and civil society are major limitations to the implementation of integrated policies concerning food security. Exemplary in this context is The Gauteng Integrated Food Security Strategy, launched by the Gauteng Department of Agriculture and Rural Development. This was the first provincial strategy in South Africa dealing exclusively with the issues of food insecurity. Although it advocates an interdepartmental collaboration, it does not specify how this can be achieved, and remains focused on a rural and agricultural paradigm [3, 5, 12, 13, 24, 25].

The state of food security in Gauteng region is of great concern; two thirds of its urban population, is probably food insecure and vulnerable to malnutrition. The burden of its consequences on health, society and economy is a cost that the province cannot afford to bear. Attempts at addressing hunger and poverty with a segregated approach which fails to recognise the complexity of the food system and its implications, can only result in short term solutions. The achievement of a resilient food security system can be obtained only through a holistic vision, which includes all the components of the food system chain, from the production to the consumption and its implications to society, health and the environment. Furthermore, the spatial scale is another feature that needs to be understood in order to correctly address food security policy [13, 21, 25].

However, cities are highly complex environments which are constituted of many different intersecting settings - no single blanket-approach can effectively address his complex interplay of settings. The necessity of specific addressed interventions is particularly required by South African cities which are not only growing very fast but also face a huge backlog of services and spatial isolation left by racial segregation and post-apartheid attempts at mass housing delivery, which has been accompanied with violence and cultural fragmentation. The complexity of modern urbanisation needs to be carefully studied in terms of its components and disparities. It cannot be approached by applying a unique "downscaling" model extended to the wider city. Food insecurity hot spots need to be identified and addressed in a tailored manner based on spatial patterns and location, and which leverages the power of agency and entrepreneurship.

The city of Johannesburg, for example, based on spatial marginalisation one might expect levels of food insecurity to be higher in impoverished settlements on the urban fringe than in the more diverse inner city: indeed $34 \%$ of households in the informal settlements of Orange Farm are severely food insecure, followed by $26 \%$ in the inner city and $21 \%$ in Alexandra, but the larger proportion of moderately food insecure households is found in the inner city. Food security at the local level in Johannesburg and Gauteng is principally related to household income and access to food. These food insecurity issues are compounded by the dietary transition mentioned earlier, which is characterised in South Africa by changes in dietary habits that accompany urban lifestyles, including increased consumption of coffee, carbonated beverages, sugar, meat, offal and potatoes $[3,10,12]$.

\section{Results/Interventions}

\subsection{Interventions}

The current agricultural production system is not delivering on the promise to feed the world, and the limitations are dire and damaging health and environmental impacts which are becoming more and more evident. Agro-ecology is increasingly being recognized as the way forward for agriculture. It is a better alternative to the destructive practices and unhealthy food produced by the industrial agriculture [1, 5].

There is enough evidence which proves that agro-ecology is the next step in solving food crises both in rural and urban areas. Initiatives of growing food in urban setting are well documented in South Africa, but more needs to be done. There are a numerous agro-based system offering in both local and national food economies. These include farmers' markets, 'farm-gate' sales, box delivery schemes, mobile shops, community supported agriculture, consumer-producer cooperatives and collective catering and canteens [5, 17].

The City of Johannesburg Food Resilience Programme Evaluation Report, proposed interventions to address food insecurity in Johannesburg these include establishment of co-operatives as hubs connecting several small farms to markets and government food supply contracts which are managed through a government food procurement company. Followed by the promotion of cheaper food products through subsidised "people's restaurants" which provide healthy and affordable meals. These restaurants are in deprived neighborhoods. Then distribution of food packages procured from small farms to deprived households and to the national school feeding programme and finally linkage of a conditional cash transfer programme to other state welfare interventions including health, education and workforce entry. The proposed intervention concurs to the IPES-Food short supply chains. Short supply chains are not just about reducing the number of intermediaries, in the supply chain nodes, but agro-ecology means distributing food through at most one intermediary node to another, putting the consumer and the producer at the heart of deciding what is produced, how it is produced, and how to define the value. A structured support and collaboration between farms close to the city is needed especially nearby farmers around Johannesburg/ Gauteng. Food distribution through short supply chains in local markets have been shown to increase income for producers, add value and generate greater autonomy for farmers, and to strengthen local economies by supporting more small businesses. This can improve the viability of small farms, reduces the carbon footprint from food distribution, and enhances household food security by giving people on low income access to good food and healthy diets, as well as encouraging customer loyalty [3, $10,13,27]$.

Households are also encouraged to grow their own food so as to supplement or compliment their dietary requirements. 
Using decomposable household refuse as growing mediums, pot planting, planting in disused bags, is recommended. Due to shortage of land to grow food, schools have enough land to carry a sizeable garden. Community-based garden situated at schools are able to contribute to the local food system of an area [10].

\subsection{The role of Public Policies and Authorities}

In South Africa policies have been enacted to address food insecurity, food access and food safety these policies include; The Integrated Food Security Strategy and the National Policy on Food and Nutrition Security, and the regional Gauteng 20-year Food Security Plan (G20YFSP) these policies are heavily underhanded by the need for capacity development as a cross-cutting need has not been adequately reflected. The other issue raised is that low to non-compliance by stakeholders, sees these policies making little impact $[3,10$, 13].

For a shift to an agro-ecological approach to happen to our food system policy and support structures at national, provincial and local level is much needed, grassroot campaigning is needed, these policies are not easily translated to the understanding of the people who are supposed to benefit from them. Policy changes should support improvements in the supply and demand of local sustainable foods, production of appropriate foods for local markets, improved infrastructure, small-scale food processing facilities, farmers' co-ops and coordinated marketing initiatives. More research into local agro-ecological production and local food economies is also needed. At a local level, authorities can help through their own purchasing policies and practices; as well as providing support through planning policies, which can be used to revitalise local shops; fiscal measures to support local sourcing, and specific initiatives to develop farmers' markets, community supported agriculture, fair trade schemes and other similar initiatives. Food safety and standards, trade and development policies have to be refocused on benefiting local communities, appropriate health and safety, food hygiene, environmental health, and labeling regulations are needed so that they do not unduly affect smaller producers and enterprises. Traceability and labeling regulations should include compulsory information about the origin of ingredients and distance travelled. Policy makers need to develop effective and suitable national, regional, and local strategies to support the development of sustainable food economies, covering the whole food chain to encourage sustainable food economies $[3,10,13]$.

\subsection{Agro-ecology Improves Urban Resilience and Creates Economic Opportunities}

Integrated into urban planning as part of multifunctional urban landscape systems, agro-ecology can provide a variety of ecosystem services which increase the resilience of urban centres to climate change impacts such as temperature extremes, flooding, high peak wind speeds air water pollution. Multifunctional urban landscape systems integrated activity nodes and corridors with a public open space system provide important ecosystem services. These ecosystem services benefit human populations directly or indirectly, from ecosystem functions, including the provision food, firewood and water, regulating the improvement of the microclimate through shade and transpiration, filtering of air, reduction of wind speeds, buffering and attenuation of storm-water, improved drainage of rainwater, enhanced soil retention of moisture, erosion control and topsoil development, nutrient cycling, enhancing cultural and social aspects through aesthetic beauty, sports and recreation, cultural events, secure and pleasant routes for non-motorised transport.. By protecting and preserving urban infrastructure from climate-change impacts, multifunctional urban landscape systems have the potential not only to reduce expenditures for maintenance of infrastructure that is the basis for social and economic activities, but actively accommodate and contribute towards economic, social and cultural activities that enhance urban resilience. As poverty always brings about further scarcity and deficiency, the creation of jobs and the achievement of greater self-reliance in terms of food and livelihoods sufficiency in the urban areas could mitigate the trend of migration to urban settlements. It is thus important to implement and sustain agro-ecology practice in both rural and urban areas [19, 20, 21, 22].

\subsection{Agro-ecology Food System, Technology Development and Extension Support}

Despite the proven advantages of resource-conserving technologies and practices such as the Agro-ecology food system, adoption by farmers can be a problem despite the obvious advantages. This is because these technologies involve the substitution of management skills, knowledge, and labour for external inputs. Participatory extension support can assist in technology transfer, because if imposed on farmers, then they will not be adopted widely. Agro-ecology food system capitalizes on local knowledge because it is a valuable and underused resource, because extension has long been grounded in the diffusion model of agricultural development with minimum farmer participation the adoption results have been minimum. Agro-ecology food system incorporates farmer participation and utilization of indigenous knowledge in the practice, with strong support mechanisms in place Agro-ecology food system using is able to improve food supply especially in an urban setting $[5,10,13,20]$.

\section{Conclusions}

Agro-ecology production system is systems approach to addressing food insecurity and promoting food resilient either in an urban or rural environment. The ecology approach is based on the application of ecology to the design and management of sustainable agro-ecosystems. It is a systems approach to agriculture and food systems development based on traditional knowledge, alternative agriculture, and local food system experiences. The most important aspect of agro-ecology is the linking of ecology, culture, economics, and society to 
sustain agricultural production, healthy environments and viable food and farming communities. This paper has highlighted the vast opportunities presented by agro-ecology as an alternative food system which can offer solution to food security and food resilient, as a buffer to the threats of climate change. To realize the benefits of the agro-ecology food system a participatory extension support system which use indigenous knowledge is critical. Agricultural support systems such as Farming Systems Approach have proven that participative and bottom up approach to farmer support yields better results $[1,5$, $13,15,17,19]$.

\section{References}

[1] Crush, Hovorka, Tevera. 2011. "Food security in Southern African Cities: the place of urban agriculture". Progress in Development $\quad 2011 \quad$ Studies 285. http://pdj.sagepub.com/content/11/4/285.

[2] Vaarst, M., Escudero, A. G., Chappell, M. J., Brinkley, C., Nijbroek, R., Arraes, N. A.,... \& Halberg, N. (2018). Exploring the concept of agro-ecological food systems in a city-region context. Agroecology and Sustainable Food Systems, 42 (6), 686-711.

[3] Kroll, F. J.; Rudolph, M. J.; Simatele, D. (2015). Gauteng City Region Observatory Food Systems Review Paper (Working Paper Series). Food Security Working Paper 1: A systemic review of food security in the Gauteng City Region. Wits Siyakhana Initiative, a division of the Wits School of Geography, Archaeology and Environmental Studies (GAES). Report Submitted June 2015.

[4] Mdee, A., Wostry, A., Coulson, A., \& Maro, J. (2019). A pathway to inclusive sustainable intensification in agriculture? Assessing evidence on the application of agroecology in Tanzania. Agroecology and Sustainable Food Systems, 43 (2), 201-227.

[5] Frison, E. A. 2016. From uniformity to diversity. Biodiversity International.

[6] Muchesa. E. 2013. Sustainable extension support to land reform beneficiaries in Zimbabwe (Mashonaland West). http://repository.up.ac.za/bitstream/handle/2263/40368/Muche sa_Sustainable_2013.pdf; sequence $=1$.

[7] De Wit, M. P., Blignaut, J. N., Knot, J., Midgley, S., Drimie, S., Crookes, D. J., and Nkambule N. P. 2015. Sustainable farming as a viable option for enhanced food and nutritional security and a sustainable productive resource base. Synthesis report. Green Economy Research Report, Green Fund, Development Bank of Southern Africa, Midrand.

[8] Béné, C., Oosterveer, P., Lamotte, L., Brouwer, I. D., de Haan, S., Prager, S. D.,... \& Khoury, C. K. (2019). When food systems meet sustainability-Current narratives and implications for actions. World Development, 113, 116-130.

[9] FAO (2016). Growing Greener Cities. www.fao.org/ag/AGP/greenercities/.

[10] Florian Kroll, Moira Beery, Orsola Segantin, Michael Rudolph (2012). Mid-Term Evaluation of the Siyazondla Homestead Food Gardens Programme. Friend of the Earth Europe (2015). Annual

Review https://www.foeeurope.org/sites/default/files/other/2015/foee annual_report_20152_0.pdf.

[11] Lawrence, M., \& Friel, S. (Eds.). (2019). Healthy and Sustainable Food Systems. Routledge.

[12] Misselhorn, A., \& Hendriks, S. L. (2017). A systematic review of sub-national food insecurity research in South Africa: Missed opportunities for policy insights. PloS one, 12 (8).

[13] Frayne, Bruce et al. 2010. The State of Urban Food Insecurity in Southern Africa. Urban Food Security Series No. 2. Queen's University and AFSUN: Kingston and Cape Town. Adapted by AFSUN from UN World Urbanization Prospectus: 2007 Revision Population Database.

[14] GCRO. 2011. Green Strategic Programme for Gauteng. Report. p 135.

[15] Greenberg. 2010. Status report on land and agricultural policy in South Africa, 2010. Institute of Poverty, Land and Agrarian Studies, School of Government, University of the Western Cape, Cape Town.

[16] Chakona, G., \& Shackleton, C. M. (2018). Household food insecurity along an agro-ecological gradient influences children's nutritional status in South Africa. Frontiers in nutrition, 4, 72. IPES-Food. 2016: A paradigm shift from industrial agriculture to diversified agro-ecological systems. International Panel of Experts on Sustainable Food systems.

[17] Rosset et Al. 2011. "The campesino-to-Campesino agroecology movement of ANAP in Cuba: social process methodology in the construction of sustainable peasant agriculture and food sovereignty". The Journal of Peasant Studies, Vol 38, No1, pp 161-191.

[18] Devereux, S. (2016). Social protection for enhanced food security in sub-Saharan Africa. Food policy, 60, 52-62.

[19] Rudolph et al. 2008. Food Security, Poverty and Health in Three Study Areas of Johannesburg. Siyakhana Initiative for Ecological Health and Food Security. Final report Wits Health Consortium.

[20] Michael Rudolph, Florian Kroll, Shaun Ruysenaar \& Tebogo Dlamini. (2012). "The State of Food Insecurity in Johannesburg." Urban Food Security Series No. 12. Queen's University and AFSUN: Kingston and Cape Town. http://www.afsun.org/wp-content/uploads/2013/09/AFSUN_1 2.pdf.

[21] Rudolph M and Kroll. F (2016). City of Johannesburg Food Resilience Programme Evaluation Final Report, Wits Commercial Enterprise, Wits Siyakhana Initiative, School of Geography, Archaeology and Environmental Studies (GAES), October 2016.

[22] Sustainable Development Goals 2016 http://www.un.org/sustainabledevelopment/sustainable-develo pment-goals/.

[23] Food Security and Agricultural Livelihoods Programme (FSALP) Final report 2015.

[24] Siyakhana Initiative for Ecological Health and Food Security. 2011. Food security position brief, unpublished document.

[25] Frayne, B., \& Crush, J. (2017). Food supply and urban-rural links in Southern African cities. In Food and Nutrition Security in Southern African Cities (pp. 34-47). Routledge. 
[26] Wilson S 2015 The risks of rapid urbanization in developing countries World Health Organisation 2015 http://www.who.int/campaigns/world-health-day/2015/event/e $\mathrm{n} /$.
[27] Zita, L. (2012). Food Security Policy (Zero Hunger Programme) for the Republic of South Africa. Presentations to stakeholders at the Department of Agriculture, Forestry and Fisheries, Pretoria, February 07, 2012. 